\title{
Los signos de los tiempos como criterio hermenéutico fundamental del quehacer teológico
}

\author{
The Signs of the Times as the Fundamental \\ Hermeneutic Criterion for Theological Task
}

Rafael Luciani $R$.

\begin{abstract}
"Atendiéndonos al consejo de Cristo Señor cuando nos exhorta a discernir los signos de los tiempos, vemos que en medio de tan calamitosas tinieblas se dan señales, y no pocas, que parecen anunciar auspicios de mejores tiempos para la Iglesia y para la humanidad"
\end{abstract}

Juan XXIII, Humanae Salutis

\section{Resumen}

Uno de los grandes interrogantes que ha movido al espíritu humano a lo largo de la historia, más allá de la pregunta por la existencia de Dios, ha sido la búsqueda de su presencia y el reconocimiento de su acción en medio de la vida social. En este ensayo - siguiendo el espíritu del Concilio Vaticano II y de Medellín - nos proponemos desarrollar cómo el quehacer teológico, especialmente su método, debe responder a la cuestión de los signos de los tiempos. Para ello, desarrollaremos el significado de esta noción y cómo fue entendida por el Concilio. Lo que implica, primero, asumir una posición frente a la posibilidad de la presencia real de Dios en la historia. Segundo, en razón del carácter simbólico e histórico de esta presencia, debemos buscar por signos visibles. Tercero, el acto de reconocimiento de estos signos históricos 
no agota la realidad siempre mayor del misterio de la auto-comunicación de Dios. Por último, el quehacer teológico, sea en su método como en su contenido, ha de ser afectado significativamente por esta búsqueda de signos reales de esperanza ante los dramas que viven las mayorías en nuestro mundo, especialmente de cara al empobrecimiento de nuestras sociedades. Una vez expuestas estas consideraciones, ofreceremos al lector un criterio que ayudará al reconocimiento y a la interpretación de la presencia actual de estos signos. Se trata de encontrar procesos actuales de humanización entre los más pobres y olvidados, para construir así relaciones fraternas y redes sociales que actualicen nuestro seguimiento a Jesús en la transformación de condiciones menos humanas a otras más humanas, como lo pidió Medellín.

Palabras clave: Signos de los tiempos. Revelación. Historia. Pobres. Concilio Vaticano II.

\section{Abstract}

One of the greatest questions that have moved human spirit throughout history, beyond the issue of the existence or not of God, has been the query of God's historical presence and action. This paper will expose - following the Second Vatican Council and Medellín - how theological task, especially its method, is affected by the question for the signs of the times. We will be developing the meaning of this notion and how the Council presents it. This implies, first, to assume a position on the possibility of God's real presence in history. Second, due to the symbolic and historical character of this presence, we have to look for visible signs. Third, the act of recognizing historical signs of God's presence does not exhaust the interpretation of the whole event of divine self-communication. Finally, all theological task will be affected significantly, as much in its method as in its content, when having the scope of searching and presenting real signs of hope in the face of our dramatic times, especially while facing our even more impoverished world. After presenting these reflections, we will encourage the readers to adopt a criterion that will help them in the process of recognizing and interpreting contemporary signs of the times. This criterion focuses on the search for existent processes of humanization among the poor and forgotten ones, inspiring us to build fraternal relationships and social bonds following Jesus` call to transform all less human conditions to more human ones. 
Keywords: Signs of the Times. Revelation. History. Poor. Second Vatican Council.

\section{Introducción: ¿dónde está Dios?}

Una de las grandes interrogantes que ha movido el espíritu y el ingenio humano a lo largo de todos los tiempos, más allá de la pregunta por la existencia o no de Dios, ha sido la de su presencia y acción, y las formas históricas de su posible manifestación, y más aún, la posibilidad de encontrar y reconocer esta presencia en la historia por parte del ser humano. Se trata de una cuestión que trasciende la mera inquietud individual, y se arraiga en la más dramática y casi inescrutable condición de sentido de los acontecimientos que van entretejiendo la historia en cada época. Esto nos hace recordar a una antigua leyenda de la literatura jasidita que cuenta cómo, una vez, una madre judía se acercó al rabino Eliezer, llevando de la mano a su hijo de pocos años. El rabino, deseoso de ganarse la simpatía del niño, le hizo una pregunta: Vamos a ver pequeño. Te doy un schekel si sabes decirme dónde está Dios. El niño respondió: Y yo te doy a ti cinco, si tú sabes decirme dónde no está1. Podemos afirmar que tanto el buen rabino Eliezer como el astuto niño tenían razón, pues en ninguno de los dos casos podemos encontrar una respuesta absoluta ${ }^{2}$.

\section{El camino a seguir}

Son cuatro, entre otros, los aspectos que más sobresalen al abordar el problema que intentamos reflexionar. Primero, el tema nos lleva a posicionarnos frente a la posibilidad y el modo de la presencia real de Dios en la historia. Segundo, esta presencia, por su carácter simbólico, ha de habérselas con su reconocimiento en fe mediante signos visibles constituidos históricamente. Tercero, este reconocimiento no agota ni garantiza la interpretación de lo donado-acontecido como teologal, es decir, como manifestación que es asumida desde el talante gratuito y salvífico de un Dios que humaniza fraternizando. Cuarto, la conformación del quehacer teológico se ve afectada,

\footnotetext{
${ }^{1}$ Leyenda jasidita citada por RUBIO, M. "Los signos de los tiempos como hermenéutica del acontecer de Dios en los acontecimientos de los hombres". Moralia 49 (1991), p. 3.

2 "Dios está en todas partes en tanto él es el que lo fundamenta todo, y no está en ninguna parte por cuanto todo lo fundado es creado". RAHNER, K. Grundkurs des Glaubens. Einführung in den Begriff des Christentums. Freiburg: Herder, 1976, p. 90.
} 
de una u otra manera, tanto en su método como en su contenido, por el hecho de reconocer e interpretar signos proféticos de esperanza a lo largo de las distintas épocas de la historia.

Si el primer planteamiento nos introduce en un dialogo serio con el mundo del agnosticismo y la increencia a partir del problema experiencial de la creación y recreación históricas, y el segundo nos inserta en aquella actitud de quien reconoce una presencia agraciante que impulsa una dinámica creyente que inspira una constante interpretación frente a lo acontecido, el tercero nos inserta en la formalización teológica de criterios de interpretación que nos ayuden a asumir a la historia de un modo teologal a partir de procesos de discernimiento histórico de una presencia que aún en su mayor distancia, no deja de estar cada vez más cerca del hombre para humanizarlo fraternizándolo.

En este sentido todo quehacer teológico que asume como criterio hermenéutico fundamental el reconocimiento e interpretación de los signos de los tiempos, ha de generar como horizonte teologal, a ser formalizado conceptualmente, a la humanización entendida aquí como la creación de condiciones históricas, tanto personales como estructurales, que posibiliten la fraternidad entre los hombres y la filiación con Dios.

\section{El encuentro: una presencia in actu}

La pérdida de la condición histórica tanto del sujeto creyente como del Dios revelado, en algunas experiencias y/o formalizaciones teológicas del cristianismo, ha producido la instauración de un pathos religioso que ha invertido la misma lógica de la encarnación propia de la autocomunicación de Dios en el mundo, para vivir de una categorización frustrante de la presencia divina que representa a Dios como un ser trascendente que interviene a su antojo en la historia de la humanidad, pero que no puede ser pensado como una realidad abarcable por nosotros ${ }^{3}$, aunque sí, paradójicamente, como un ente que puede intervenir en nuestra historia. Ciertamente esta inversión religiosa desposiciona y desubica religiosamente al cristianismo de su lugar natural de encuentro con lo divino, es decir, de la historia y su entretejido de acontecimientos que la constituyen, como realidad. La contradicción es

\footnotetext{
${ }^{3}$ Como afirma Karl Rahner, la dificultad radica en que "Dios se nos presenta como el siempre trascendente, como el que precede a todo lo puesto, y que por tanto no puede pensarse de nuevo como puesto, como un ente abarcado o abarcable por nosotros". RAHNER, K. Grundkurs des Glaubens. Einführung in den Begriff des Christentums. Freiburg: Herder, 1976, p. 89.
} 
inmediata, como lo expresa K. Rahner en su Grundkurs des Glaubens, "la dificultad consiste en que Dios por definición parece no poder estar allí donde nosotros estamos por definición. Toda objetivación de Dios, como algo indicable y determinable en el espacio y en el tiempo, en el aquí y ahora, parece que por esencia no es Dios, sino algo que nosotros hemos de inferir como fenómeno a partir de otros fenómenos que deben indicarse o pueden postularse dentro del mundo"4. Un primer problema surge, entonces, por el modo como nosotros podemos comprender el término presencia referido a Dios, en otras palabras, el modo de estar de Dios en el mundo. En este sentido el problema no se centra tanto en la presencia de Dios ipso facto en la creación, sino en el modo de estar de Dios en nuestra historia teniendo en cuenta, como cauce hermenéutico, qué de Dios está hoy presente o no en el mundo, in $a c t u^{5}$.

\subsection{La inversión necesaria: el modo de estar de Dios en el mundo}

Esto nos lleva a una primera inversión de nuestra experiencia categorial religiosa, de un Dios que interviene a un Dios presente. Si el modo de darse de Dios realmente al mundo es la autocomunicación ${ }^{6}$, el problema se complica

\footnotetext{
4 "Die Schwierigkeit besteht nämlich darin, dass Gott per definitionem nicht da sein zu können scheint, wo wir per definitionem sind. Jede Objektivation Gottes scheint als raumzeitlich Angebares, als Bestimmbares, das hier und jetzt ist, wesentlich nicht Gott zu sein, sondern etwas, das von uns als Phänomen aus anderen innerweltlich angebaren oder zu postulierenden Phänomenen hergeleitet werden muss". RAHNER K. Grundkurs des Glaubens. Einführung in den Begriff des Christentums. Freiburg: Herder, 1976, p. 89.

${ }^{5}$ Como bien expone Sobrino: "no es lo mismo repetir, hasta la saciedad, que Dios está presente en la historia, como afirmación teológica verdadera y trascendental, que determinar qué de Dios está hoy presente en la historia, haciéndose notar como presente". SOBRINO J. "Los signos de los tiempos en la teología de la liberación”. In: LERA, J. M. (ed.). Fides quae per caritatem operatur. Homenaje a Juan Alfaro sj en su 75 cumpleaños. Bilbao: Univ. Deusto - Mensajero, 1989, p. 253.

${ }^{6}$ El término autocomunicación tiene una incidencia directa en la elaboración de una teología de la gracia, importante para comprender la forma de la presencia de Dios en la historia. La teología escolástica había explicado la experiencia de la Gracia como un acto extrínseco de Dios apropiado al Espíritu y donado a través de él al ser humano. Esto implicaba una teología de la Gracia en cierta forma cosificada y extrínseca. ¿Si Dios se autocomunica, la Gracia, que es El mismo, no se da al ser humano como un donarse de Dios mismo más que un recibir "algo" de Dios? Ciertamente. La teología de la Gracia en Rahner realizará una relectura de los términos aristotélicos aplicados para explicar esta experiencia de la Gracia y afirmará que la Gracia no puede ser una causalidad formal pues eliminaría toda diferencia ontológica entre el hombre y Dios, pero tampoco puede ser concebida desde la causalidad eficiente, como lo proponían los neo-escolásticos, ya que cosificaban la Gracia y la concebían como una comunicación
} 
aún más, ya que lo que está en juego es la relación misma que acontece entre Dios y la creaturalidad, antes que lo dado o manifestado y formalizado conceptualmente. Tomás de Aquino, en su Comentario a las Sentencias de Pedro Lombardo, distingue con gran ingenio, que mientras las criaturas se relacionan con Dios mediante tres modos distintos: por semejanza (creación), por fe y gracia, y por la unión hipostática (encarnación); Dios se relaciona con las criaturas realmente, en un acto único, por presencia, potencia y esencia, pues en él no existe división, sino simplicidad ${ }^{7}$. Ahora bien, la criatura es capaz de esta relación, en la medida en que este orden natural tiene una disposición y ordenación constitutivas hacia su fin último y providente. En este sentido el modo como Dios está presente en el mundo es el modo mismo como el mundo está constituido y dispuesto hacia $\operatorname{Dios}^{8}$, en términos de Tomás, sería providencialmente ${ }^{9}$, como una disposición intrínseca al mundo que permite expresar y justificar la posibilidad de la presencia de Dios en lo creado. Es por

extrínseca de Dios al hombre. ¿Cómo salvar el lenguaje Trinitario, desde la autocomunicación de Dios, en función de su donación como Gracia al ser humano?. Rahner recurre a otro término: la causalidad cuasi formal. Con este otro término se trata de aclarar el primer término que define el movimiento revelatorio de Dios, a saber, el de autocomunicación, en base a tres aspectos que podemos explicar brevemente: (a) Se trata de la autocomunicación de Dios donde, como Revelador, permanece como realidad soberana, no comprensible totalmente en cuanto Misterio. Por tanto, no puede existir una igualdad ontológica entre el Creador y las creaturas; (b) La autocomunicación del Dios Trino que se abre y revela al ser humano, se hace presente en la historia como Verdad que actúa históricamente. Lo que hace en la historia (su hacer) no es algo extrínseco a su ser, sino la donación de lo que es en sí mismo. Dios no se realiza en la historia en cuanto Dios, no necesita de la historia para ser el que es, pues su autocomunicarse es libre y gratuito, no por necesidad. Se mantiene la trascendencia de Dios respecto de la historia; (c) Esta autocomunicación no lo reduce a una creatura, se dona como Amor gratuito y es esta experiencia la que hace posible y define su relación con el ser humano. Dios, en cuanto que es Amor, espera una respuesta de Amor en la aceptación de su Misterio expresado en la historia. Así, el término de causalidad cuasi formal ayuda a aclarar el otro de autocomunicación, implicando una relación particular, propia y esencial de cada Persona divina con la realidad creada. La Gracia, es pues, Dios en sí mismo que se dona al hombre totalmente, y no algo que Dios crea para dárselo extrínsecamente al hombre. Cfr. RAHNER, K. "El Dios Trino como principio y fundamento trascendente de la historia de la salvación”. In: FEINER, Johannes; LÖHRER, Magnus. Mysterium Salutis II. Madrid: Cristiandad, 1977, pp. 286-287.

${ }^{7}$ Cfr. Tomás de Aquino, In primum sententiarum, Distinctio 37, q.1 a.2 sol.

8 "Deus enim est in rebus temporaliter per modum rerum, sed res ab aeterno in Deo per modum Dei; quia omne quod in altero est, est in eo per modum eius in quo est, et non per modum sui”. Tomás de Aquino, In primum sententiarum, Distinctio 37, q.2 a.3 ad 3.

9 "Providentia est ipsa divina ratio in summo omnium principe constituta, quae cuncta disponit. Dispositio autem potest dici tam ratio ordinis rerum in finem, quam ratio ordinis partium in toto". Tomás de Aquino, Summa Theologiae I-I q.22 a.1 sol. 
ello que Rahner puede concluir que lo categorial e histórico es una auténtica y real manifestación de la autocomunicación de Dios en el mundo, de su presencia y acción, pero en tanto esto acontece en una interrelación subjetiva e histórica de la criatura con Dios, y sólo dentro de esta forma puede estar Dios presente en el mundo, pues se hace presente dentro de la condición histórica propia de lo humano ${ }^{10}$. Sólo así un acontecimiento histórico, interpretado como signo de una presencia divina, puede ser objetivado como presencia real de la acción divina, en tanto enmarcado dentro de una relación subjetiva y epocal con Dios, y nunca fuera de ella.

\subsection{La vía antropológica de la realidad histórica}

En este mismo horizonte, la constitución pastoral sobre la Iglesia en el mundo, Gaudium et Spes, promulgada por el Concilio Vaticano II, asume la vía antropológica para descubrir la dimensión constitutivamente teologal de la realidad, que se gesta desde la más dramática tensión polar, propia de una auténtica libertad, que acontece entre lo que ha de ser la vocación humana y la facticidad dramática de su realización histórica. El camino es claro. Primero se nos invita a tener presente al "mundo de los hombres, es decir, la familia humana entera con el conjunto universal de las realidades entre las que ésta vive" 11 . Para hablar de la presencia de Dios en el mundo hay que partir del mundo en cuanto presente en toda su dramaticidad recreadora, pero del mundo del hombre, es decir, de "el gozo y la esperanza, las tristezas y angustias del hombre de nuestros días, sobre todo de los pobres y de toda clase de afligidos" ${ }^{12}$, pero en cuanto y en tanto "son también gozo y esperanza, tristezas y angustias de los discípulos de Cristo, y nada hay verdaderamente

\footnotetext{
10 “Con esta presencia categorial de Dios se dice sólo que allí donde el sujeto permanece realmente sujeto con su experiencia religiosa trascendental y se realiza como tal, esas objetivaciones de la intervención de Dios reciben un valor dentro de la experiencia trascendental del hombre, valor que ciertamente corresponde a tales fenómenos en sí, pero les corresponde en tanto ellos se encuentran con toda verdad en una interrelación subjetiva y, consecuentemente, sólo dentro de dicha interrelación subjetiva pueden conocerse en esa peculiaridad suya que es inherente a los mismos". RAHNER, K. Grundkurs des Glaubens. Einführung in den Begriff des Christentums. Freiburg: Herder, 1976, p. 95.

11 "Mundum igitur hominum prae oculis habet seu universam familiam humanam cum universitate rerum inter quas vivit". Concilio Vaticano II: Gaudium et Spes 2.

12 "Gaudium et spes, luctus et angor hominum huius temporis, pauperum praesertim et quorumvis afflictorum”. Concilio Vaticano II: GS 1 .
} 
humano que no tenga resonancia en su corazón"13. Si bien es cierto que la posibilidad de la presencia histórica de Dios sólo de él depende, no es menos cierto que el modo de esta presencia no es otro que lo humano y su vocación específica, en cuanto asumido desde su propia dinámica real. Es por ello que el mismo Concilio "ofrece a todo el género humano la sincera cooperación de la Iglesia para forjar la fraternidad universal que corresponde a esta vocación"14. Pues no existe otro modo de la presencia divina que aquél que podemos denominar la fraternidad entre los hombres como camino para la filiación con el Dios de la Vida.

\subsection{Signos de los tiempos y presencia de Dios en el mundo}

Hasta aquí podemos inferir una primera acepción importante de lo que podemos entender con la expresión signos de los tiempos, cuyo significado viene expuesto con claridad en la misma Gaudium et Spes: "El pueblo de Dios, movido por la fe, según la cual cree que, en medio de los acontecimientos, exigencias y deseos de que participa juntamente con los hombres de nuestro tiempo, es conducido por el Espíritu del Señor que llena el universo, se esfuerza por discernir en todas estas cosas cuáles son los signos verdaderos de la presencia o de los planes de Dios" ${ }^{15}$. Si el modo de manifestarse de Dios es a través de los mismos acontecimientos, exigencias y deseos de la humanidad, hemos de estar atentos al segundo problema, el del reconocimiento de este modo de manifestarse de Dios, ante lo que se hace imprescindible y "necesario, por tanto, conocer y comprender el mundo en que vivimos y sus esperanzas, sus aspiraciones, su modo de ser, frecuentemente, dramático"16. Esto implica una inversión en el camino que nos pueda conducir al reconocimiento de esta presencia, ya que hemos de toparnos con la realidad, en cuanto teologal, es decir, capaz de Dios, para saltar a su lectura teológica, qué de Dios está en ella

\footnotetext{
13 "Gaudium et spes, luctus et angor etiam Christi discipulorum, nihilque vere humanum invenitur, quod in corde eorum non resonet”. Concilio Vaticano II: GS 1.

14 "Generi humano sinceram cooperationem Ecclesiae offert ad instituendam eam omnium fraternitatem quae huic vocationi respondeat". Concilio Vaticano II: GS 3.

15 "Populus Dei, fide motus, qua credit se a Spiritu Domini duci qui replet orbem terrarum, in eventibus, exigentiis atque optatis, quorum una cum ceteris nostrae aetatis hominibus partem habet, quaenam in illis sint vera signa praesentiae vel consilii Dei, discernere satagit". Concilio Vaticano II: GS 11 .

16 "Oportet itaque ut mundus in quo vivimus necnon eius exspectationes, appetitiones et indoles saepe dramatica cognoscantur et intelligantur”. Concilio Vaticano II: GS 4.
} 
presente, in actu. Esta es la dinámica del quehacer teológico, en cuanto praxis primera y fontal de toda formalización e interpretación teológicas. Es la lógica del reconocimiento teológico de la realidad en cuanto dramática e histórica.

Sólo así podemos alcanzar el tercer aspecto, la formalización teológica de un criterio que nos ayude a explicitar la presencia agraciante del Dios de la Vida. Se trata del momento de la interpretación y el discernimiento donde el instante y su forma histórica es superado por el sentido siempre mayor y agraciante de la presencia que lo fundamenta y recrea continuamente. En este sentido, podemos afirmar, con la Gaudium et Spes, que "para realizar este cometido pesa sobre la Iglesia el deber permanente de escrutar a fondo los signos de los tiempos e interpretarlos a la luz del Evangelio"17. Este acto reflexivo del espíritu y el ingenio humano de escrutar los signos de los tiempos, carga con una finalidad muy específica dentro del quehacer teológico.

Aquí nos topamos con una segunda acepción importante de la expresión estudiada. Sólo a la luz del Evangelio estos acontecimientos pueden ser reconocidos e interpretados. Es aquí cuando la realidad en cuanto vivida teologalmente, es decir, como capaz y constitutiva de Dios, pasa a ser formalizada teológicamente, y confrontada, a su vez, con aquello que de Dios en ella se revela como verdad última para todo ser humano. Lo evangélico no es una añadidura hermenéutica o un accesorio que nos proporciona ciertos criterios para leer la realidad y conocer sus misterios, sino, ante todo, el criterio de buena nueva, comunicado en la vida y palabras de Jesús de Nazaret, el carpintero, el Cristo, en quien Dios ha querido revelar al hombre el propio misterio de su humanidad y las exigencias que esta revelación de lo humano comporta para toda persona en cada tiempo.

\section{La búsqueda de un criterio de reconocimiento}

Esto nos lleva al cuarto aspecto anteriormente señalado, el de la búsqueda de un criterio evangélico último que oriente el contenido propio de una semántica cristiana del tiempo y dé forma al quehacer teológico. Juan XXIII, en la Convocatoria del Concilio Vaticano II el día 25 de diciembre de 1961, nos aporta un criterio importante en nuestro camino: "atendiéndonos al consejo de Cristo Señor cuando nos exhorta a discernir los signos de los

\footnotetext{
17 "Ad tale munus exsequendum, per omne tempus Ecclesiae officium incumbit signa temporum perscrutandi et sub Evangelii luce interpretandi”. Concilio Vaticano II: GS 4.
} 
tiempos, vemos que en medio de tan calamitosas tinieblas se dan señales, y no pocas, que parecen anunciar auspicios de mejores tiempos para la Iglesia y para la humanidad"18. He aquí un tercer aspecto, y quizás el más importante porque informa al quehacer teológico de un modo particular, que nos permite avanzar en el significado de la expresión signos de los tiempos. Se trata de reconocer y discernir aquellos acontecimientos que orienten a la humanidad hacia su real y auténtica humanización, que no es otra cosa que la realización de la vocación humana en la fraternidad universal mediante la cooperación de la Iglesia y de toda la humanidad en general.

No estamos ante signos o sucesos emotivos, de carácter individual, frutos de un imaginario religioso que busca su propia verdad huyendo de lo humano para ampararse bajo una pseudodivinidad que falsea la propia realidad hasta el grado de deshumanizarla en torno a un supuesto proyecto de espiritualización. En este sentido, la misma justificación que el texto de la Gaudium et Spes da sobre la relevancia del discernimiento de los signos de los tiempos es la búsqueda de soluciones plenamente humanas como expresión honesta y sincera de los planes de Dios: "pues la fe lo ilumina todo con una nueva luz y manifiesta el divino propósito sobre la vocación integral del hombre, y por eso dirige la inteligencia hacia soluciones plenamente humanas"19.

He aquí el reto de un quehacer teológico contemporáneo que pretende asumir, tanto en su horizonte epistemológico como en su método, a los signos de los tiempos como criterio fundamental para el desarrollo de una hermenéutica que permita descubrir el sentido teologal de la propia historia y la responsabilidad que esto exige en la realización de la vocación humana. Aquello que de Dios se manifiesta in actu en la historia de la humanidad no puede ser otra cosa que la propia urgencia de la realización plena y feliz de la vocación humana, que nace de la exigencia frente a la deshumanización y pauperización de tantos millones de personas a lo largo de la historia de la humanidad. Con razón afirma Medellín, partiendo de una exigente analogía fundamentada en la propia dinámica recurrente de la revelación que: "así como otrora Israel, el primer Pueblo, experimentaba la presencia salvífica de Dios cuando lo liberaba de la opresión de Egipto, cuando lo hacía pasar el mar y lo conducía hacia la tierra de la promesa, así también nosotros, nuevo Pueblo de

18 JUAN XXIII. Humanae Salutis. Convocatoria del Concilio Ecuménico Vaticano II, 25 de Diciembre de 1961.

19 "Fides enim omnia novo lumine illustrat et divinum propositum de integra hominis vocatione manifestat, ideoque ad solutiones plene humanas mentem dirigit”. Concilio Vaticano II: GS 11 . 
Dios, no podemos dejar de sentir su paso que salva, cuando se da el verdadero desarrollo, que es el paso, para cada uno y para todos, de condiciones de vida menos humanas, a condiciones más humanas" ${ }^{20}$. En este sentido los signos de los tiempos decantan un triple movimiento. Por una parte hablan de Dios, pero en negativo, como clamor elevado al cielo por aquellos que siguen viviendo en condiciones infrahumanas.

Por otra parte, Dios se revela en estos signos como quien está padeciendo con (compasión) los más pobres y marginados de nuestra sociedad ${ }^{21}$. Finalmente, el reconocimiento de esta realidad que exige humanización ha de ser un acto profético y eclesial, que asuma el lenguaje del testimonio y la crítica evangélica. Si este criterio dota de una forma específica al modo de estar de Dios en el mundo, como quien salva humanizando y, más aún, a la formalización teológica de esta presencia, como el Dios de la vida y la liberación, entonces ¿lo que de Dios pueda estar presente en el mundo, puede acontecer de cualquier forma? ¿Puede todo revelar o decir algo acerca de Dios?.

\subsection{De los atributos a la esencia}

Si la forma histórica de la revelación de Dios implica ya una dinámica particular que conforma el modo cómo Él se nos revela y lo que, a él, mediante esa manifestación histórica, puede ser atribuido, in actu, acerca de sí mismo, entonces no cualquier acontecimiento o signo, suceso o experiencia pueden ser dichos que son de Dios, que le pertenecen esencialmente, ni interpretados como signo de los tiempos. Pues lo que en estos acontecimientos se nos revela, lo que está en juego, es algo que supera lo categorial y espacial, para revelar el modo mismo como Dios es-actuando, ya que en Dios no hay contradicción entre sus atributos (Vida, bondad, etc) y su actuar (Vivificando, humanizando, etc).

Si la revelación de Dios en la historia es realmente de Dios, y no una mera trascendentalización que busca dar un sentido consolador, pero en el fondo frustrante, a los acontecimientos dramáticos que suceden, entonces aquello que en la historia se revela (autocomunica) de Dios, esa búsqueda por

${ }^{20}$ CELAM. Medellin. Conclusiones de la Segunda Conferencia General del Episcopado Latinoamericano, Introducción 6.

${ }^{21}$ Cfr. RUBIO, M. "Los signos de los tiempos como hermenéutica del acontecer de Dios en los acontecimientos de los hombres". Moralia 49 (1991), p. 17. 
el qué de Dios se nos revela, nos lleva a afirmar que lo revelado en el aquí y ahora $(u b i)$ es realmente, y no sólo conceptualmente, presencia auténtica de una sustantividad (quid) divina, de lo que Dios es, y por tanto, la exigencia a su respuesta será tan grande como la esencia de donde emana, el amor. En este sentido la realización de la vocación humana, revelada en los atributos dados a Dios a partir de su actuar histórico, no son algo opcional ante Dios, sino algo que constituye realidad en lo creado en cuanto se vive como existiendo en y con Dios, siendo por y para los demás.

\section{Hacia una semántica del tiempo: de lo teologal a lo teológico}

Esto nos sitúa frente a la problemática de una posible semántica del tiempo expresada bajo el célebre enunciado signos de los tiempos, y que se gesta entre los acontecimientos históricos y su interpretación como signos de una presencia histórica de una realidad última y determinante para la realización de la vocación humana. Según la clásica definición escolástica la forma característica de un signo es la de un aliquid quod stat pro aliquo, algo que está en lugar de otro, diferente de sí. Los griegos lo denominaron un síntoma o indicio de una realidad que se revela visiblemente a través de ciertos fenómenos o hechos, como una fiebre puede indicar que una persona está enferma.

En este sentido, algo es constituido en signo sólo cuando alguien lo interpreta como signo de algo diferente ${ }^{22}$, es decir, que un signo es un "indicio evidente del que pueden extraerse deducciones con respecto a algo latente" 23 . Los acontecimientos que nos suceden, y que entretejen a la historia personal y de la humanidad, no son signos de los tiempos por sí mismos, de un modo natural, sino en cuanto reconocidos teologalmente como tales e interpretados teológicamente dentro de un horizonte de humanización.

Hablar de una semántica del tiempo implica reorientar el problema de la presencia y acción de Dios en la historia a sus justas coordenadas de reconocimiento e interpretación de la realidad histórica. En este sentido asumir a los signos de los tiempos como criterio hermenéutico fundamental para el quehacer teológico, implica reconocer al sujeto histórico concreto, con sus esperanzas y frustraciones, con su drama y gloria, como condición real de revelación de Dios en su autocomunicación al mundo.

\footnotetext{
${ }^{22}$ Cfr. ECO, U. Semiótica y filosofía del lenguaje. Barcelona: Lumen, 1990, p. 22.

${ }^{23}$ ECO, U. Semiótica y filosofía del lenguaje. Barcelona: Lumen, 1990, p. 21.
} 
Los procesos de interpretación no se refieren a la instauración de relaciones privadas y emotivas entre los acontecimientos y la posibilidad de leer en ellos una presencia mayor. La interpretación es, ante todo, un proceso mediante el cual lo dicho, el síntoma, lo acontecido, es asumido desde el sujeto que habla y que es afectado por los acontecimientos. En la interpretación de una semántica del tiempo "se trata de ver a través del lenguaje qué pasa con el hombre que lo habla" 24 . Lo que se dice y expresa el signo es el acontecimiento, pero lo dicho y expresado en él, es la revelación de lo teologal que, aunque está dado previamente ${ }^{25}$, ha de ser traducido y expresado, posteriormente, en categorías teológicas acordes a cada época, con los diversos tiempos históricos. Lo teologal no es una añadidura a lo histórico como momento a posteriori que nace de la propia experiencia, sino lo originario que, siendo fundamento y principio, sólo puede ser ahondado y reconocido como dato histórico en su precariedad y relatividad epocal.

Parafraseando a P. Ricoeur podemos decir que así como el símbolo da qué pensar, los acontecimientos históricos, en cuanto simbólicos, dan que pensar, nos introducen en la dinámica de quien se siente inquieto e interpelado y quiere decantar lo sucedido, buscando nexos y articulaciones epocales que permitan ir construyendo un sentido a lo largo de la diversidad de lo vivido. Los signos de los tiempos son acontecimientos históricos y sociales, que, en palabras de M.D. Chenu, están referidos a "fenómenos generalizados que contienen una esfera de actividades y expresan las necesidades y aspiraciones de la humanidad presente" 26 y que "pueden revelar en mayor o menor escala, con mayor o menor claridad, la presencia y acción de Dios"27. Estos acontecimientos no portan en sí un contenido semántico previo por descubrir, no contienen un destino por descifrar, ni una determinación específica del querer de $\operatorname{Dios}^{28}$, sino que nos introducen en el mundo de la interpretación

\footnotetext{
${ }^{24} \mathrm{KUSCH}, \mathrm{R}$. Geocultura del hombre americano. Argentina: Ed. Fernando García Cambeiro, 1976, 107.

25 "Hay en el proceso del habla, entonces, un referente que diría está antes del acontecimiento. Se refiere hacia atrás, hacia el trasfondo que condiciona el existente, eso mismo que es costumbre cuyo significado es el habitar en el mundo". KUSCH, R. Geocultura del hombre americano. Argentina: Ed. Fernando García Cambeiro, 1976, p. 110.

${ }^{26}$ AA.VV. La Iglesia en el mundo actual. Bilbao: Desclée de Brouwer, 1968, pp. 104-105. Cfr. CHENU, M. D. "Les signes des temps”. Nouvelle Revue Théologique 87 (1965), pp. 29-39.

27 PELLEGRINO, M. "Signes des temps et réponse des chrétiens". La Documentation Catholique 64 (1967), pp. 144-154.

${ }^{28}$ Como recuerda Chenu, a los signos de los tiempos no hay que etiquetarlos sobrenaturalmente.
} 
que brota de la libertad de un proceso creyente de humanización que se va gestando en medio de las más dramáticas decisiones que vamos tomando a lo largo de nuestras historias de vida, aún sabiendo que, tal vez, no llegaremos a soluciones felices ni claras en esta historia.

Ningún acontecimiento o suceso histórico es inmediatamente, ipso facto, un signo de los tiempos, sino en cuanto y en tanto sea reconocido en fe como tal por una comunidad eclesial que lo asume como salvífico en su propio proceso creyente ${ }^{29}$. Más aún, ningún signo de los tiempos me indica el modo específico y relativo a como cada uno, personalmente, ha de vivir la voluntad de Dios en el mundo, como si esta respondiera a un proceso de descifrar lo que en un supuesto destino ya Dios tiene previsto para cada uno; sino que manifiesta, como acontecimiento histórico que me afecta, una presencia que, en cuanto es reconocida personalmente, ha de ser asumida en la forma como se ha manifestado (en su sustantividad, su quid), antes que en el lugar categorial y específico donde se ha manifestado (ubi). Dios, al revelarse, da a conocer el modo cómo actúa y, de esa manera, cómo es él. Al hombre le queda el camino de una larga e insaciable búsqueda, siempre intranquila, exigente y dramática, del dónde, de llegar a la certeza de un lugar categorial e histórico en el que se reconozca, de forma eficaz, una tal presencia divina. De ahí que el problema nos remita, nuevamente, a la claridad de un criterio que nos ayude a comprender el modo como Dios se autocomunica, en cualquier lugar y tiempo.

\subsection{La sustantividad de la presencia: el ubique y el clamor de los pobres}

A este punto nos topamos necesariamente con otra cuestión que ha de orientar a todo quehacer teológico. Se trata, más que identificar los posibles signos de los tiempos que actualmente nos interpelan, de formalizar un criterio hermenéutico que nos permita reconocer, siempre y en todo lugar,

Lo que importa en ellos no es el hecho en sí, sino la toma de conciencia que provoca en un grupo de personas en una determinada época. Cfr. CHENU, M. D. "Les signes des temps". Nouvelle Revue Théologique 87 (1965), pp. 29-39.

29 "El conjunto sólo deviene ST cuando el hombre los hace tales, cuando los re-conoce, cuando toma conciencia de que dicho conjunto es algo más y algo diferente a la suma de los elementos aislados. Todavía más: el fenómeno deviene ST por cuanto que es registrado como tal por la conciencia humana, pero no de manera individual sino como talante colectivo (...). Lo fáctico del hecho en sí ha quedado trascendido como acontecimiento para muchos". RUBIO, M. "Los signos de los tiempos como hermenéutica del acontecer de Dios en los acontecimientos de los hombres". Moralia 49 (1991), p. 14. 
la presencia real de Dios en la historia. Y digo siempre y en todo lugar, pues como argumenta San Anselmo con gran elegancia lógica, Dios no está sólo en algunos sitios y en otros no, lo que crearía un dualismo que terminaría condicionando el amor gratuito al mérito individual, sino que, por parte de Dios, su presencia ha de concebirse como un estar esencialmente por doquiera $(\text { ubique })^{30}$, es decir, en una existencia, en el sentido de que no sólo está en todos los lugares, sino también en toda existencia histórica, creatural, y esta ha de ser la forma de su reconocimiento, como quien está, realmente, en su presencia a partir de la propia realidad existente, en nuestras experiencias y acontecimientos, en todo tiempo y lugar. Siguiendo a Anselmo, la forma existente de la historia, en cuanto realidad que hace presente a Dios, será la forma misma de quien se hace presente realmente. Es decir, que no hay otro camino, por parte del hombre, para reconocer la presencia real de Dios y su acción, que el de la economía salvífica, el de la propia existencia humana tomada en serio.

Sin embargo, ¿es posible decir que Dios está más en un lugar que en otro? Para ello debemos ahondar en la semántica del término ubique usado por Anselmo y Tomás, al referirse a Dios como quien está por doquiera. Antes que nada no se trata de una noción universal o generalizante de la presencia de Dios, que lo diluye en un todo trascendental que carece de realidad. Se trata de un término que implica una correlación donde el modo de estar de Dios en el mundo es el modo como el mundo clama a Dios en relación con la realización de la vocación humana.

El término ubique está compuesto por dos elementos que nos pueden ayudar en la estructuración de la reflexión teológica. Indica un lugar categorial -ubi- y una realidad sustancial -quid- ${ }^{31}$. Dios no está de modo absoluto en el

${ }^{30}$ Cfr. San Anselmo, Monologio, cap. 22-23. Anselmo siempre usa la expresión "ubique et semper" para referirse al modo como Dios está esencialmente en la existencia. Por una parte está esencialmente, es decir, realmente, con todo su ser, al modo de una presencia real. Por otra parte está esencialmente, pero en la existencia, es decir, que la condición en la que está y determina su forma de estar, es la existencia histórica en la que se revela autocomunicándose. Por ello puede afirmar, haciendo uso de una elegante analogía, "qualiter summa omnium essentia ubique et semper et nusquam et nunquam, id est in omni et nullo loco aut tempore sit, iuxta diversorum intellectum concordem veritatem" (cap. XXII).

31 "La afirmación que queremos hacer es que el lugar del quehacer teológico es el lugar en que acaecen los actuales signos de los tiempos; y ese lugar es el mundo de los pobres. Con ello queremos decir que el lugar de la teología, no debe entenderse primariamente como un ubi (lugar categorial), sino como un quid (realidad sustancial). El quehacer teológico debe hacerse en último término en la realidad del mundo de los pobres, sea cual fuere su lugar 
lugar físico y categorial donde se revela, sino de modo relativo, a un sujeto, a una época, a una historia, pero su estar en un determinado lugar revela una realidad sustantiva que ya deja de ser tangible para el ser humano y adquiere un valor absoluto, pues comienza a revelar algo que esencialmente pertenece a Dios.

Esta reflexión nos lleva a una conclusión que coloca al cristianismo en un auténtico drama, porque el Dios en el que creemos es el Dios revelado. El Dios de la Vida, de la Justicia, de la Paz, de la Misericordia, de los pobres, es el Dios que da vida, que hace justicia, que consuela, que perdona, que fraterniza. El Dios en el que creemos es el Dios que humaniza mediante la fraternidad y la filiación.

¿Es posible identificar, entonces, un tal criterio que nos oriente en el reconocimiento e interpretación de los signos de los tiempos a la luz de los evangelios? ¿un criterio, que por ser evangélico, no sólo pueda revelar lo que Dios quiere, su voluntad, sino lo que Dios hace in actu al revelarse, en su relación con los hombres?

El criterio no se refiere al lugar, sino a aquello que entrecruza transversalmente todo lugar, como su talante y horizonte. En este sentido, si decimos que actualmente la deshumanización y pauperización del mundo se levanta como un signo que urge y clama la presencia salvífica de Dios, su presencia reconciliadora y vivificadora, donde la paz y la justicia se abracen, entonces, "el ubi debe estar transido del quid. Se haga donde se haga empíricamente, la teología tiene que dejarse afectar hondamente por la realidad de los pobres. Su sufrimiento es lo que tiene que dar que pensar, su esperanza es lo que tiene que configurar el talante salvífico de toda teología cristiana. En otras palabras, la teología puede hacerse en muchos lugares físicos, pero tiene que hacerse desde la realidad de los pobres" ${ }^{32}$, pues como afirma el Concilio Vaticano II en la Lumen Gentium: "la Iglesia abraza a todos

categorial inmediato". SOBRINO, J. "Los signos de los tiempos en la teología de la liberación". In: LERA, J. M. (ed.). Fides quae per caritatem operatur. Homenaje a Juan Alfaro sj en su 75 cumpleaños. Bilbao: Univ. Deusto - Mensajero, 1989, p. 261.

32 SOBRINO, J. "Los signos de los tiempos en la teología de la liberación”. In: LERA, J. M. (ed.). Fides quae per caritatem operatur. Homenaje a Juan Alfaro sj en su 75 cumpleaños. Bilbao: Univ. Deusto - Mensajero, 1989, p. 262. También se puede ver a: MORENO REJÓN, F. "La Iglesia ante los nuevos signos de los tiempos. Una lectura de la Relación final del Sínodo de 1985”. Páginas vol XI (1986), pp. 6-11. En este artículo se mencionan a los pobres y a la presencia de las nuevas iglesias como nuevos signos de los tiempos que claman ante su reconocimiento pastoral en la vida y misión de la Iglesia. 
los afligidos por la debilidad humana, más aún, reconoce en los pobres y en los que sufren la imagen de su Fundador pobre y doliente, se esfuerza en aliviar sus necesidades y pretende servir en ellos a Cristo" ${ }^{33}$.

El creyente puede reconocer a Dios en muchos lugares, pero en aquellos lugares en donde lo reconozca como realmente presente, de ese modo ha de habérselas con Dios y su modo de ser. De otra manera caeríamos en un docetismo, en una auténtica tragedia, sin salida, que haría de la historia una gran mentira montada en un escenario, sería la representación absurda de la negación de toda lógica de la encarnación, y de la condición histórica de la revelación divina.

En este sentido, una teología que toma en serio la presencia y la acción de Dios mediante el reconocimiento y la interpretación de signos de los tiempos, está asumiendo a la realidad histórica como fuente real de revelación ${ }^{34}$, actualizada en cada época mediante los acontecimientos que entretejen su trama histórica, y leída junto a las fuentes tradicionales y a la luz del Evangelio.

\section{A modo de conclusión: humanización y fraternidad}

En el año 1963, el Papa Juan XXIII, en su encíclica Pacem in Terris, escribía unas palabras pronunciadas por Pío XII, que siguen siendo actuales para nuestra realidad y en las que aparece un dato relevante que nos puede ayudar a identificar este criterio, se trata de la fraternidad, como forma histórica de cualquier proceso de humanización que permita leer el desarrollo salvífico de la humanidad en el entretejido de los acontecimientos que suceden: "queremos que estos hombres tengan presente que el crecimiento paulatino de todas las cosas es una ley impuesta por la naturaleza y que, por tanto, en el campo de las instituciones humanas no puede lograrse mejora

33 "Ecclesia omnes infirmitate humana afflictos amore circumdat, imo in pauperibus et patientibus imaginem Fundatoris sui pauperis et patientis agnoscit, eorum inopiam sublevare satagit, et Christo in eis inservire intendit”. Concilio Vaticano II: Lumen Gentium 8.

34 "Los ST constituyen una fuente de revelación que manifiesta también a Dios; no como en las otras fuentes - Escritura o Tradición -, sino en la misma realidad histórica y social y de acuerdo con su peculiar idiosincrasia (...). El acontecer de los hombres se convierte así y de manera no-convencional en ámbito de la manifestación de Dios". RUBIO, M. "Los signos de los tiempos como hermenéutica del acontecer de Dios en los acontecimientos de los hombres". Moralia 49 (1991), p. 23. También se puede leer el artículo bajo la responsabilidad del Secretariado General de la revista Concilium titulado: "Signos de los tiempos". Concilium 25 (1967), pp. 313-322. Especialmente la página 314 cuando se refiere a los signos de los tiempos como fuente de reflexión teológica. 
alguna si no es partiendo paso a paso desde el interior de las instituciones. Es éste precisamente el aviso que da nuestro predecesor, de feliz memoria, Pío XII, con las siguientes palabras: No en la revolución, sino en una evolución concorde, están la salvación y la justicia. La violencia jamás ha hecho otra cosa que destruir, no edificar; encender las pasiones, no calmarlas; acumular odio y escombros, no hacer fraternizar a los contendientes, y ha precipitado a los hombres y a los partidos a la dura necesidad de reconstruir lentamente, después de pruebas dolorosas, sobre los destrozos de la discordia" ${ }^{35}$.

El criterio no puede ser otro que el de la humanización, entendida esta como la creación histórica de la fraternidad, tanto personal como estructuralmente, en cuanto realiza la imagen y semejanza divina en el ser humano, para dar gloria a Dios dando vida a los hombres. Es a partir de este criterio que el Concilio Vaticano II puede reconocer como signos que parecen atestiguar y dar credibilidad a la presencia in actu de Dios a la santidad personal, las aspiraciones de la libertad religiosa, el respeto por la dignidad del ser humano, el martirio, la urgencia de formas de cultura más humanas y la búsqueda de la paz internacional ${ }^{36}$. En este sentido, una teología de los signos de los tiempos, no puede aceptar cualquier medio para llegar a un fin último, por más humano y loable que pueda ser dicho fin. Sólo cuando existe una correlación auténtica entre los medios y el fin último, entonces podemos hablar de signos auténticos de credibilidad de la presencia y la acción de Dios en la historia, ya que dicha correlación ha de ser libremente asumida y construida por cada sujeto, mediante la fraternidad personal y estructural, y nunca puede ser impuesta por algún individuo como no lo ha sido tampoco por parte de Dios, quien habiendo creado todo bueno, dejó el dominio del mundo a la libertad de los procesos de humanización del hombre y de la mujer. En esta perspectiva un signo puede ser reconocido como provocación profética que llama a la esperanza y a la vida, cuya intencionalidad es manifestar la gloria de Dios en la gloria del hombre.

\footnotetext{
${ }^{35}$ Juan XXIII. Pacem in Terris, 162.

${ }^{36}$ Cfr. FISICHELLA, R. La revelación, evento y credibilidad. Ensayo de teología fundamental. Salamanca: Sígueme, 1989, pp. 368-369. También el autor hace mención a la solidaridad y el silencio como nuevos signos de los tiempos en FISICHELLA, R. "Los signos de los tiempos en el contexto contemporáneo”. Medellín 65 (1991), pp. 55-71. También Walter Kern se expresa de la libertad y el futuro como signos actuales de los tiempos, en la medida en que la libertad horizontal de la vida se nos concede y descubre a través del futuro vertical de Dios. Cfr. KERN, W. "Zukunft und Freiheit als theologische Kriterien". Zeitschrift fûr Katholische Theologie 95 (1973), pp. 186-199.
} 
Sólo así las sabias palabras de Qohélet pueden alcanzar un reposo verdadero, honesto y feliz, cuando con gran drama afirma en una expresión desgarradora: "Vanidad de vanidades, todo es vanidad" (Qo 1,2). Sólo así el sinsabor real ante la vida y el crecimiento de signos de deshumanización y desestructuración de las sociedades y sus instituciones pueden alcanzar algún sentido y comenzar a sembrar esperanza, para no caer en la pesadumbre de aquella otra lamentación: "entregué mi corazón al desaliento, por todos mis fatigosos afanes bajo el sol"'(Qo 2,20). Sólo una realidad en la que reconozcamos signos de los tiempos puede dejar de clamar "¿qué ganancia tiene el hombre en todas las fatigas con que se afana bajo el sol?" (Qo 1,3), pues no se trata de una actitud pesimista, ni absurda frente a un mundo deshumanizado, sino de reconocimiento de la relatividad histórica y su descreación que clama ante Dios por condiciones de vida más humanas, pero que necesitan del esfuerzo y la colaboración libre de cada ser humano para su realización.

Esto significa retomar con hondura y profecía aquellas palabras de Jesús cuando responde a los fariseos y saduceos que querían ver una señal milagrosa que viniera del cielo: "Al atardecer decís: va a hacer buen tiempo, porque el cielo tiene un rojo de fuego. Y por la mañana decís: hoy tendremos mal tiempo, porque el cielo tiene un rojo sombrío. ;De modo que sabéis discernir el aspecto del cielo y no podéis discernir los signos de los tiempos" (Mt 16,1-3). La irrupción del Reino en Jesús revela la exigencia de lo revelado en sus signos, en el entretejido de los acontecimientos como llamada urgente a construir el mensaje de humanización pronunciado en la sinagoga por Jesús (según nos relata Lc 4), y no porque sea sólo una exigencia que venga del hombre, sino porque sólo la revelación de Dios puede manifestar su brillantez total cuando todos y cada uno de los hombres podamos vivir verdadera y plenamente como humanos. Los signos de los tiempos actualizan la experiencia creyente en un acto continuo e insaciable de búsqueda y discernimiento, superando toda visión determinista y mágica de la divinidad, provocando el paso de la letra muerta a la buena nueva, en fin, "cuando esa fe que se vuelve tradición nos va conduciendo a la verdad que humaniza a nuestros hermanos y nos compromete definitivamente, sabemos que en ella está Dios presente y guiándonos. Revelándonos la verdad del hombre que debe ser"37.

\footnotetext{
${ }^{37}$ SEGUNDO, J. L. "Revelación, fe, signos de los tiempos". In: SOBRINO, J.; ELLACURÍA, I. (ed.). Mysterium Liberationis I. Madrid: Trotta, 1994, pp. 466.
} 


\section{Referencias bibliograficas}

AA.VV. La Iglesia en el mundo actual. Bilbao: Desclée de Brouwer, 1968.

CHENU, M. D. “Les signes des temps". Nouvelle Revue Théologique 87 (1965).

CELAM. Medellín. Conclusiones de la Segunda Conferencia General del Episcopado Latinoamericano.

CHENU, M. D. “Les signes des temps". Nouvelle Revue Théologique 87 (1965).

CONCILIO VATICANO II. Constitución pastoral Gaudium et Spes sobre la Iglesia en el mundo actua. Constitución dogmática Lumen Gentium sobre la Iglesia.

ECO, U. Semiótica y filosofía del lenguaje. Barcelona: Lumen, 1990.

FISICHELLA, R. "Los signos de los tiempos en el contexto contemporáneo". Medellín 65 (1991).

FISICHELLA, R. La revelación, evento y credibilidad. Ensayo de teología fundamental. Salamanca: Sígueme, 1989.

JUAN XXIII. Humanae Salutis. Convocatoria del Concilio Ecuménico Vaticano II, 25 de Diciembre de 1961.

JUAN XXIII. Pacem in Terri.

KERN, W. "Zukunft und Freiheit als theologische Kriterien". Zeitschrift fûr Katholische Theologie 95 (1973), pp. 186-199.

KUSCH, R. Geocultura del hombre americano. Argentina: Ed. Fernando García Cambeiro, 1976.

LERA, J. M. (ed.). Fides quae per caritatem operatur. Homenaje a Juan Alfaro sj en su 75 cumpleaños. Bilbao: Univ. Deusto - Mensajero, 1989.

MORENO REJÓN, F. “La Iglesia ante los nuevos signos de los tiempos. Una lectura de la Relación final del Sínodo de 1985”. Páginas vol XI (1986).

PELLEGRINO, M. "Signes des temps et réponse des chrétiens". La Documentation Catholique 64 (1967).

RAHNER, K. "El Dios Trino como principio y fundamento trascendente de 
la historia de la salvación”. In: FEINER, Johannes.; LÖHRER, Magnus. Mysterium Salutis II. Madrid: Cristiandad, 1977.

RAHNER, K. Grundkurs des Glaubens. Einführung in den Begriff des Christentums. Freiburg: Herder, 1976.

RUBIO, M. "Los signos de los tiempos como hermenéutica del acontecer de Dios en los acontecimientos de los hombres". Moralia 49 (1991).

SAN ANSELMO, Monologio.

SEGUNDO, J. L. "Revelación, fe, signos de los tiempos". In: SOBRINO, J.; ELLACURÍA, I. (ed.). Mysterium Liberationis I. Madrid: Trotta, 1994.

SOBRINO J., "Los signos de los tiempos en la teología de la liberación". In: LERA, J. M. (ed.), Fides quae per caritatem operatur. Homenaje a Juan Alfaro sj en su 75 cumpleaños. Bilbao: Univ. Deusto - Mensajero, 1989.

TOMÁS DE AQUINO. In primum sententiarum; y Summa Theologiae.

Rafael Luciani $R$.

Doctor en Teología Dogmática en la Universidad Pontificia

Gregoriana

Profesor Titular de la Universidad Católica Andrés Bello (Caracas)

Professore Straordinario por la Pontificia Salesiana (Roma)

Visiting Professor en el Boston College (Boston, MA)

Boston / MA - U.S.A

E-mail: lucianir@bc.rdu

Recebido em: 29/09/15

Aprovado em: 19/10/15 